Artículo de reflexión

Cuestiones de Filosofía

ISSN: 0123-50-95

E-ISSN: $2389-9441$

Vol. 5 - Nº 24 Enero- junio, año 2019

pp. 129-144

\title{
Ensino de filosofia na encruzilhada: democracia, atualidade e antropofagia
}

Philosophy teaching is in the crossroad: democracy, actuality, and anthropophagy

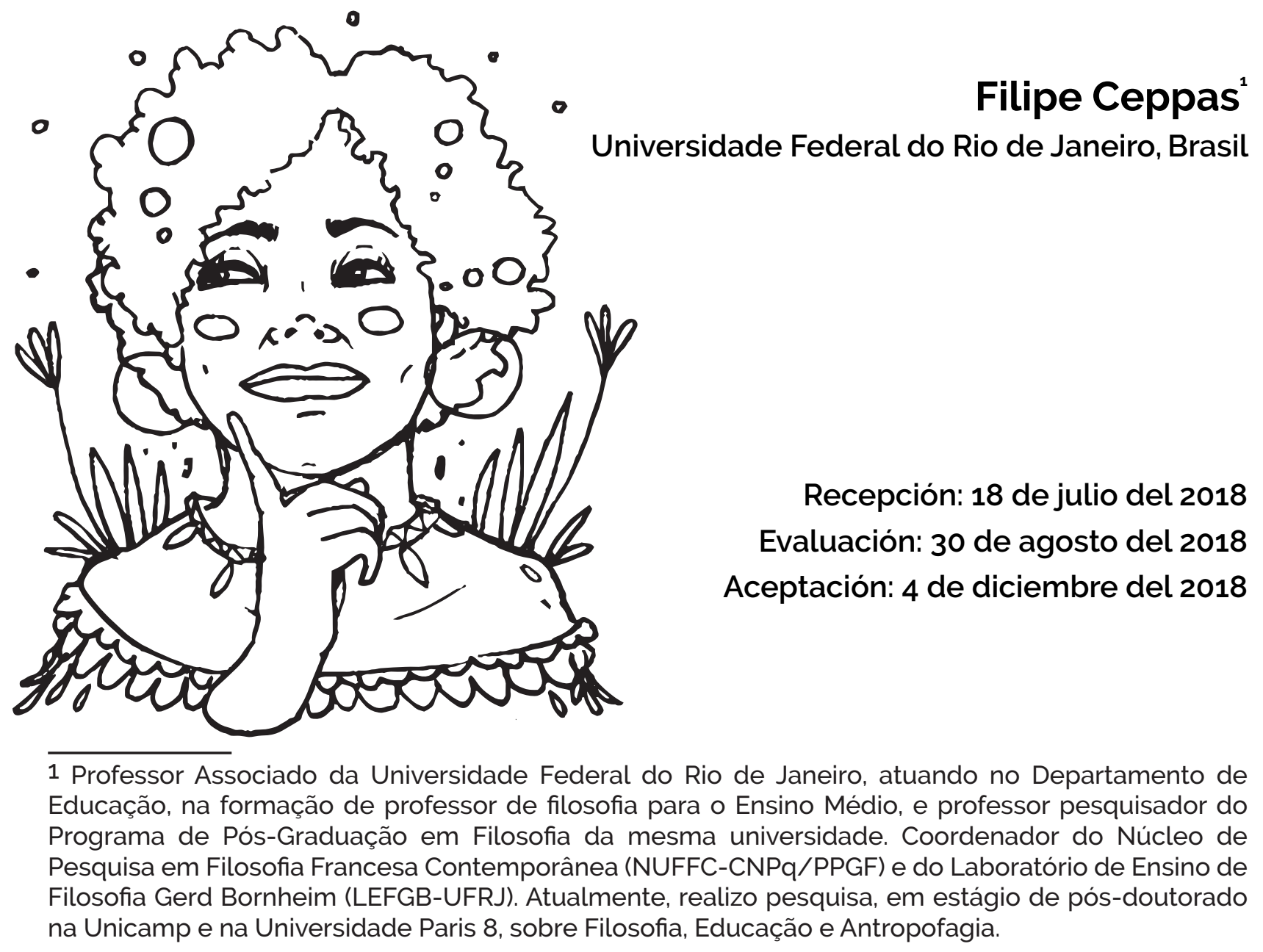




\section{Resumo}

O que pode significar ensinar filosofia no ensino médio numa sociedade como a brasileira? "Preparar para a cidadania"? Este texto apresenta elementos e questões no intuito de nos ajudar a repensar alguns aspectos centrais deste problema. Admitindo que filosofia e democracia são termos indissociáveis, o texto procura indicar porque seria preciso repensá-los a partir do princípio de que suas tensões não se resolvem apenas com mais e melhor "esclarecimento". Neste sentido, duas outras dimensões essenciais do debate são chamadas a comparecer para ajudar a pensar a tarefa da formação escolar da filosofia: a questão da relação entre filosofia e atualidade, com o auxilio de Walter Benjamin, e a questão de uma possivel apropriação da herança indigena na cultura americana, através do projeto antropofágico de Oswald de Andrade, enquanto plataforma teórica e cultural que nos ajudaria a reconhecer e ultrapassar os limites de uma "formação escolar e filosófica europeia".

Palavras-chave: Ensino de filosofia, democracia, atualidade, antropofagia.

\section{Abstract:}

What can philosophy teaching mean in high school education in society as the Brazilian one? Does it prepare for citizenship? This paper presents elements and questions to help us to rethink several main aspects of this problem. We have to admit that philosophy and democracy are inseparable terms. This paper wants to indicate why it would be necessary to rethink both terms from the point that their tensions are not solved with more or better "clarification". Other two essential dimensions of the debate are called to help to think about the task of scholar formation of philosophy: the question about the relationship between philosophy and actuality, with the help of Walter Benjamin, and the question of a possible appropriation of the indigenous inheritance in the American culture, through the anthropophagy project of Oswald of Andrade. As a theoretical and cultural platform, this would help us to acknowledge and surpass the bounds of a "European, scholar and philosophical formation".

Key-word: Teaching of philosophy, democracy, current affairs, anthropophagy. 


\section{Enseñanza de la filosofía en la encrucijada: democracia, actualidad y antropofagia}

\section{Resumen:}

¿Qué puede significar enseñar filosofia en la enseñanza media en una sociedad como la brasilera? ¿Preparar para la ciudadania? Este texto presenta elementos y cuesiones con la intencion de ayudarnos a repensar algunos aspectos centrales de este problema. Admitiendo que filosofia y democracia son terminos indisociables, el texto busca indicar por qué sería necesario repensarlos a partir del principio de que sus tensiones no se resuelven solo con más o mejor "esclarecimiento". En este sentido, otras dos dimensiones esenciales del debate son llamadas a comparecer para ayudar a pensar la tarea de la formación escolar de la filosofía: la cuestion de la relación entre filosofia y actualidad, con el auxilio de Walter Benjamin y la cuestion de una posible apropiación de la herencia indigena en la cultura americana, a traves del proyecto antropogágico de Oswald de Andrade, como plataforma teórica y cultural que nos ayudaría a reconocer y superar los límites de una "formación escolar y filosófica europea".

Palabras clave: Enseñanza de la filosofía, democracia, actualidad, antropofagia.

\section{Enseigner la philosophie à la croisée des chemins : démocratie, actualité et anthropophagie}

\section{Résumé :}

Qu'est-ce qu'enseigner peut-cela signifier dans l'enseignement au niveau secondaire dans une société comme celle du Brésil ? Cela peut instruira la citoyenneté ? Ce texte présente d'éléments et de situations avec l'intention de nous aider à repenser quelques aspects centraux appartenant à ce problème-là. En admettant que Philosophie et Démocratie sont des terms indissociables, le texte a pour but indiquer pourquoi serait-il indispensable de le repenser à partir du faite que leurs tensions ne peuvent être mieux résolues qu'avec la « clarification. » Dans ce point, d'autres deux dimensions essentiels du sujet sont amenées à aider à penser le travail qui signifie la formation scolaire de la philosophie : la question de la relation entre philosophie et actualité, avec l'aide de Walter Benjamin ; et la question d'une 
possible appropriation de l'héritage indigéne dans la culture américaine, à travers du projet anthropophage d'Oswald de Andrade, comme plate-forme théorique et culturelle qui bien nous aiderait à reconnaitre et à surmonter les limites d'une « formation scolaire et philosophique européenne. »

Mots-clés : Enseignement de la philosophie, de la démocratie, de l'actualité, de l'anthropophagie.

\section{Ensino de filosofia, democracia e iluminismo}

"É preciso reinventar o ensino de filosofia!" / "É preciso reinventar a democracia!" / "Precisamos de uma filosofia tropical não iluminista!" / "Precisamos de uma filosofia... antropófaga!" - Alguém lança essas palavras de ordem em algum lugar da desordem tropical... Ao trabalho!

É possivel (necessário?) pensar numa democracia para além (ou aquém) dos marcos do pensamento ocidental? 0 que de nossa cultura, também africana e indigena, vislumbramos como potentes para um pensar outro, não iluminista, capaz de nos ajudar a reinventar a democracia? Seria essa uma exigência evidente para a filosofia - e para o ensino de filosofia - nos trópicos? Podemos reinventar o uso de palavras como "filosofia" e "democracia"? Como essas palavras gregas, esse "amor à sabedoria", esse "poder do povo", podem atender aos nossos anseios, às nossas necessidades? Se, do ponto de vista grego (e não falamos sempre sobretudo desde esse "ponto de vista", a partir dessa herança como algo que se dá a ser visto e que nos ajuda a ver? Como algo evidente?), a filosofia não apenas nasce com a democracia, mas seria também essencialmente democrática, dialógica; se, nela, na filosofia, pensamento e política são dois lados de uma mesma moeda; se a filosofia, como disse Jean-Pierre Vernant (1986), é "filha da cidade", e se confunde com a própria ideia da moeda, com a medida, com aquilo que limitaria o ilimitado, a riqueza, a tirania; não seria preciso desconfiar, igualmente, que esta imagem herdada, e sua prática, seu ensino e aprendizado, e a política da qual ela seria inseparável, também sempre foram e ainda são, em grande medida (qual medida?), incapaz de romper ou evitar as hierarquias, as dominações tirânicas, autoritárias, sobretudo do poder da moeda, da riqueza, e isso desde os seus primórdios? 
Diante do mundo sempre o mesmo segundo a medida (Heráclito, frag.30), diante dessa medida da justiça, do lógos, a multidão sem lógos é o todo desordenado, que está dormindo, e deste todo, aparentemente, só vem indiferença, escárnio ou mesmo ódio. "Evidente", diria Platão, porque não se pode fazer bem duas coisas ao mesmo tempo, e a multidão precisa trabalhar, quando não está por demais ocupada com seus próprios interesses egoístas, com as suas sombras (ver Rancière, 2003). A filosofia esteve desde sempre em tensão na pólis. A vida-morte de Sócrates seria o grande arquétipo desta tensão. De certo modo, "a filosofia ocidental" foi sempre um eterno repensar a questão mesma desta partilha: pensar o ser não se distingue de decidir quem e como se é capaz de pensá-lo -estando por isso acordado, sendo por isso superior- em oposição àquele que, por não sê-lo, está dormindo e é inferior, bom apenas para fazer, para trabalhar, para obedecer. Metafísica e divisão econômico-social costumam andar sempre de mãos dadas. Esse jogo de luz e sombra, constitutivo da filosofia, como contorná-lo, como dele se desviar e nele se reinventar? Somos capazes de desfazer essa tensão no interior da própria filosofia, de sua prática, de seu ensino e aprendizado? Seria possivel escapar desta tensão, desta herança, e fazer filosofia, e ensiná-la e aprendê-la, para além (ou aquém) desta herança, desse algo que se dá a ser visto e que nos ajuda a ver, ... dessa evidência? Restaria, então, alguma coisa desse "amor à sabedoria", ou seria necessário pensar, praticar, um outro tipo de amor, uma outra sabedoria e um outro poder do povo?

É linda a definição aristotélica da pólis como uma "comunidade de iguais que visa aquilo que é o melhor para todos" (mas alguns são sempre "mais iguais que outros", nos diz a experiência ordinária). Não é ainda, e sempre, em nome de uma certa igualdade, e de uma certa justiça, de um certo bem, que justificamos o ensino de filosofia? Não o fazemos em nome do desenvolvimento das capacidades de qualquer um? E esse desenvolvimento pode ser entendido até mesmo como uma necessidade? Trabalhar com a filosofia já existente, com aquilo que se reconhece em geral como sendo filosofia (e não apenas suas mais diversas teorias, doutrinas, mas também suas atitudes, o que já não é tão evidente), pensar de certos modos e a partir do que já foi pensado, genericamente, aprender com a história da filosofia é tido como uma espécie de "alfabetização cultural" indispensável para participar de algum modo, de um modo responsável, dessa ágora difusa que chamamos "sociedade". Conhecer minimamente Platão, Thomas Hobbes, Jean-Jacques Rousseau, Michel Foucault, Judith Butler (ou, ainda, Oswald de Andrade, Eudoro de Souza, Willem 
Flusser - o que também já não é tão evidente, tamanha a dificuldade que temos de incorporar em nossos currículos pensadores e pensadoras que se encontram à margem do cânone da história da filosofia) seria equivalente a ter um aprendizado "básico" em matemática, nas ciências, nas artes. Mas por que a multidão teria algo a ver com essa responsabilidade, com essa participação? Não estamos, aqui, em pleno sonho iluminista de uma ampliação das luzes com vistas a um "mundo melhor"?

Essa perspectiva iluminista parece estar ancorada em pressuposições universalistas acerca do "homem" e suas questões (a justiça, o bem, o belo, a verdade, etc), mas sobretudo na ideia de que todo ser humano tenderia (ou deveria tender) naturalmente a aquiescê-las em seu espírito. ${ }^{2} \mathrm{Se}$, entretanto, como defendeu Deleuze, filosofar não é algo natural, que aconteça espontaneamente, e sim algo a que somos sempre forçados por algum encontro, por um incômodo, algo exterior à própria filosofia (um problema, que é o horizonte onde ela se realiza), não haverá nunca garantia de que estejamos aptos a (ou desejosos de) fazê-lo. Filosofar, então, significa, em primeiro lugar, algo paradoxal: significa fazer algo para o qual ainda não sabemos se estamos preparados para fazer. Filosofar, sobretudo no contexto da escola, numa perspectiva não iluminista, não universalista, com uma multidão, com todos e qualquer um que não somos "nós", os já iniciados nos meandros e mistérios da tradição filosófica, grega, ocidental, significa um esforço para pensar não necessariamente contra essa tradição, mas para além ou aquém dela. Situar-se aquém ou além do já pensado é criar um espaço para que pensemos juntos algo novo, ou que pensemos de modo novo o já pensado. É implicar alunos e alunas no processo. É não dar nenhum passo que não esteja ancorado num movimento que implique os próprios estudantes -um exercício que eles aceitem fazer, uma questão que eles se empenhem por debater, uma narrativa que eles demonstrem interesse por conhecer, etc.

A diferença de uma tal aposta com a perspectiva universalista não parece residir tanto em conteúdos ou métodos, mas antes nos pressupostos e na finalidade. $\mathrm{Na}$ perspectiva universalista, iluminista, por ser a reflexão que mais propriamente (mais essencialmente) se debruça sobre as questões mesmas "da justiça", "da ética", "da

2 Uso aqui o termo "iluminismo" num sentido vago, associado entretanto à pressuposição precisa da perfectibilidade humana, elegendo a razão como o próprio do homem e como sua principal virtude. É bom lembrar que, para alguns dos ditos "filósofos iluministas", essas pressuposições não são nada evidentes. 
política", etc, a filosofia deveria possibilitar que todos aqueles e aquelas que entrem em contato com ela, segundo suas condições e capacidades, se tornem pessoas igualmente interessadas em defender "a justiça", "a ética", pensando e agindo politicamente de modo consequente com esse interesse. A filosofia, segundo essa perspectiva, deve possibilitar que alunos e alunas se apropriem de um instrumental (temas, questões, argumentos, sentimentos, etc) que irá, no limite, ajudá-los a tomar uma posição mais firme e coerente no mundo, etc. Mas há ao menos dois pontos cegos nessa conjugação de filosofia, educação e política, proposta em nome dos universais da filosofia e da cidadania. O primeiro é a falácia da pressuposição de uma relação de causalidade simplista entre saber e poder: a crença de que, porque sou capaz de desvendar os mecanismos das injustiças, me torno não apenas interessado, mas, no limite, capaz de lutar contra elas, contra os abusos do poder (econômico, político, jurídico, etc), em favor da ética, etc. O segundo ponto cego está na falácia correlata da pressuposição de que quem eventualmente não se submete a esta evidência é porque não vê corretamente o problema, porque não percebe que, sem uma comunidade de iguais que visa o que é melhor para todos, a sociedade sucumbe à violência e ao ilimitado do poder da natureza, ao ilimitado da riqueza desigual. Esses dois pressupostos, tidos como evidências, muitas vezes se confundem com a ideia mesma de democracia e a relação que a filosofia guarda com esta.

Mas conceber a democracia como contenção de poderes ilimitados através de mecanismos de alternância dos governantes não significa render-se a esses pressupostos problemáticos. $O$ trabalho de Rancière o demonstra. A democracia, segundo esse autor, não pressupõe nenhum desvelamento das engrenagens da injustiça, nem descansa na busca de um consenso em torno de uma comunidade de iguais capaz de decidir o que seria o melhor para todos. A democracia, para Rancière, é o fundamento de um poder sem fundamento (Rancière, 2014). Ela existe somente enquanto puro movimento de contenção do ilimitado do poder, afirmação de uma igualdade já dada de fato na capacidade de fala, pensamento e experiência de qualquer um, independente de saber ou posição. E mais: a democracia como afirmação da igualdade não significa a simples participação de qualquer um na governança, ela se dá somente quando a participação de não importa quem interrompe a lógica da dominação. Essa é, do meu ponto de vista, a democracia que 
interessa a um ensino de filosofia não iluminista. Mas ela tampouco nos é suficiente. No dia a dia da sala de aula, e nos mais variados contextos em que a filosofia é chamada para participar pedagogicamente na construção de um coletivo capaz de se contrapor à lógica da dominação, nos interpelam também a atualidade e nosso caldo cultural nos trópicos, caldo que (como veremos ao final do texto) acredito poder qualificar de "antropófago". Qual "atualidade" seria esta?

\section{Sintonia com o atual: Walter Benjamin}

Filosofar com os alunos e as alunas implica estar sintonizado com uma sensibilidade que os constitui ou que os atravessa de algum modo. Tal como a sociologia, a antropologia, as artes, a tradição filosófica tem um vasto repertório de teorias e atitudes com relação a essa questão. Filosofar no século XXI é saber se situar, existencialmente, praticamente, num cenário pós-moderno de disputas as mais diversas, de desejos e atenções impossiveis de serem domesticados, de múltiplas experiências e temporalidades, de violência, consumo, privilégio da imagem, do digital, crise do meio ambiente, conflitos de gênero, etc. Há um desafio, uma responsabilidade do professor para com os alunos, no que diz respeito à atualidade, àquilo que "faz liga" com o fluxo de todas as coisas e as experiências dos alunos, com as experiências de todos nós (as redes sociais, os modismos, a distopia, o antropoceno, as misérias, etc), que é também uma responsabilidade para com o pensamento, para com aquilo que no pensamento é modificado, transformado pela atualidade. Então, a primeira consideração importante com relação a este desafio, de "estar sintonizado com a atualidade", com a "sensibilidade dos alunos", é que ele não se enfrenta necessariamente (e talvez quase nunca) tratando de "temas da atualidade", mas estando atento para (e deixando-se permear por) aquilo que há de atual no pensamento, o que constitui ou atravessa o pensamento na contemporaneidade.

Walter Benjamin resumiu, de certo modo, esse compromisso com a atualidade como sendo o compromisso político do pensador, o que ele chamou de "vontade frenética dos intelectuais de sair do estágio das eternas discussões e chegar a uma decisão a qualquer preço..." (Benjamin, 1986, p.106). Benjamin foi um marxista sui generis. Ele abriu novos caminhos para o marxismo, e uma de suas principais contribuições foi 
a exploração de um tipo de pensamento revolucionário que, tal como nos exorta a $11^{\text {a }}$ tese sobre Feuerbach, de Marx, não seria apenas contemplativo, mas um pensamento que estaria antes atravessado ou constituido por imagens e mais de acordo com o desenvolvimento técnico industrial. No texto "O surrealismo. O último instantâneo da inteligência européia", Benjamin começa falando do desafio político, de forma premonitória, em 1929, pouco tempo antes da subida de Hitler ao poder, como o desafio de "organizar o pessimismo":

...organizar o pessimismo não é outra coisa senão expulsar da politica a metáfora moral e descobrir, no espaço da ação política, um espaço inteiramente construido de imagens. Tal espaço imagético já não pode ser mensurado contemplativamente. Se a dupla tarefa da inteligência revolucionária é derrubar a hegemonia intelectual burguesa e estabelecer o contato com as massas proletárias, ela falhou quase inteiramente quanto à segunda parte da tarefa, pois o contato já não pode ser estabelecido de maneira contemplativa. (idem, p.114, grifo nosso)

A mensuração imagética, revolucionária, não contemplativa, confunde-se em Benjamin com a iluminação dos pormenores. Trata-se de parte essencial de sua plataforma teórico-política, que trabalha a potência da teoria sempre a partir da atenção aos detalhes, às ruínas, ao que é relegado ao esquecimento, à história dos vencidos. Adorno chamou a atenção para essa atração de Benjamin aos "componentes petrificados, congelados ou obsoletos da cultura" (Adorno, 1998, p.228), ao seu "método microscópico e fragmentário", onde "a menor célula da realidade (...) equivalia ao resto do mundo todo". Para Benjamin, continua Adorno, "interpretar fenômenos de modo materialista significava menos explicá-los a partir da totalidade social do que relacioná-los imediatamente, em sua individuação, a tendências materiais e lutas sociais". (idem, pp.232-233)

Benjamin é bastante conhecido por sua famosa tese da perda da aura, desenvolvida em textos como "A obra de arte na época de sua reprodutibilidade técnica", "Pequena história da fotografia" e nos escritos sobre Baudelaire. A perda da aura é o abandono de uma certa estrutura do olhar -onde impera o valor de culto; a aparição única de uma coisa distante, por mais próxima que ela esteja-, mas Benjamin afirma, também, que a aura é, paradoxalmente, uma certa radicalização desta estrutura numa direção inesperada. A intensidade ou a força da aparição única 
de uma coisa se desloca para a exploração do atlas ampliado das grandes cidades e da reprodutibilidade, na iluminação de seus contornos inconscientes, coletivos, microscópicos; uma exploração da "saudável alienação do homem com seu mundo ambiente". Na organização pessimista de um mundo marcado pela catástrofe, pela alienação, pela reificação, a intimidade do mundo burguês fechado em seu estojo não tem mais lugar; seu espaço deve ser forçamente transformado pela educação política e pública, no convívio com a "iluminação dos pormenores".

Trata-se do aprofundamento da percepção dos mecanismos inconscientes atuantes na própria construção das imagens e que lhes dá significação e valor. A reprodutibilidade permite toda uma gama de aproximações a aspectos perceptivos, óticos, hápteis, quedizem respeito a umnovo paradigma microscópicoefragmentário, que sequestra as imagens, a arte e a experiência de modo geral, transformando sua natureza. É algo que começa com o fósforo, com a técnica que possibilita, com um clique, a realização de uma tarefa complexa. O clique da câmera cinematográfica possibilita a captação da imagem do ator riscando o fósforo ou acendendo o isqueiro (é um dos exemplos que Benjamin nos dá), como um clique que se espelha em outro, ampliando nossa percepção dessa estrutura "mágica" naturalizada, possibilitando sentir o metal do isqueiro em nossos dedos. A reiteração de cliques no celular replica a ação de ascender o fósforo ou o isqueiro e ilumina todo o universo fragmentado nos quadradinhos das redes sociais. A reprodutibilidade amplia as sensações ao concentrar a atenção no pormenor, espelhando o universo inteiro.

Benjamin extrapola o conceito freudiano do inconsciente em uma versão materialista. $\mathrm{Na}$ verdade, o inconsciente é menos ótico do que háptil, tátil, contrariamente à visão, sentido quase sempre imediatamente associado à contemplação. ${ }^{3} \mathrm{~A}$ análise do fenômeno da fotografia ajuda a reconhecer essa superação do domínio da contemplação na cultura. Para Benjamin, a questão de se a fotografia é ou não arte foi uma questão rapidamente superada, sendo mais importante mostrar como a fotografia se torna paradigma para pensar a arte. A "arte como fotografia" significa, então, ampliação ou reconfiguração de nossa própria capacidade de percepção artística, estética, sensivel, do mundo, para além do aumento da autopercepção, 3 ..em tempos históricos de grandes mudanças, as tarefas que se apresentam ao aparelho receptivo humano não podem ser resolvidas por meio puramente ópticos, ou seja, pela contemplação. Elas só podem ser resolvidas gradualmente pela recepção tátil, pelo costume" ("A obra de arte na era de sua reprodutibilidade técnica", 2012, p.31) 
percepção da nossa percepção. ${ }^{4}$ Isto é, a reprodutibilidade técnica possibilita pensar "a arte como fotografia" não no sentido de que a fotografia torna-se o paradigma do ato de "retratar" o que existe, como um instantâneo de nossa percepção estética, sensivel; mas, antes, como interação, construção, reconfiguração de imagens (o que fica mais evidente com a montagem, mas também nas miniaturas e nos hibridos artísticos) e da percepção; arte como reconfiguração da percepção (por vezes ampliação em direção ao mínimo, não ao máximo). Essas ideias de Benjamin nos ajudam a conceber a atualidade do pensamento desde uma perspectiva ao mesmo tempo política, metafísica e estética.

Benjamin nos ajuda a calibrar nossa intervenção filosófico-pedagógica em termos de uma sensibilidade com relação ao "atual", dentre outros aspectos, porque essa experiência do olhar na pós-modernidade se banaliza e encontra-se, de certo modo, gasta, por assim dizer, invizibilizada no hiperconsumo atual das imagens (assim como na música, tão importante na experiência estética ordinária da contemporaneidade). Não se trata de querer aproximar, do exterior, filosofia e aquilo que os jovens "curtem", o hip-hop, as redes digitais, o facebook, etc. Trata-se de perguntar o quanto podemos nos aproximar desses conteúdos de modo imanente, enquanto linguagens que dizem respeito a formas de percepção e desafios políticos e existenciais. Não se trata simplesmente de valorar o uso do cinema, da música, da fotografia, dos jogos eletrônicos, como recurso pedagógico; nem de querer qualificar de fora, "criticamente", as experiências estéticas ordinárias de todos, como se um verniz de teoria fosse conferir dignidade e superioridade a coisas que em si mesmas não necessariamente as têm (ou que nunca deixaram de ter). Trata-se, antes, de atentar para o que há de filosófico nessas linguagens e em suas experiências, enquanto formas diferenciadas e emancipadoras de compreensão e trabalho de expressão, de estar no mundo, para além do viés argumentativo, demonstrativo, teóricocontemplativo.

O trabalho conceitual, argumentativo, teórico, é parte indissociável de um curso de filosofia, mas ele não seria o "elemento principal", nem sua finalidade última. Ele é parte constitutiva de um todo em que figuram também o trabalho junto à

4 E pouco importa que, para que isto ocorresse, a produção artística, sobretudo literária, com Zola ou Balzac, já tivesse preparado o terreno para que o cotidiano, o ordinário, o vulgar, fosse acolhido como arte, como afirma Rancière (2009). Isso em nada reduz a especificidade da potência dos novos meios de reprodução. 
sensibilidade. E a dimensão imagética e estética da contemporaneidade não é apenas "tópico curricular" ou "estratégia didática" para atrair a atenção. Ela é parte constitutiva de um possivel filosofar com os alunos, com as alunas. A construção efetiva de coletivos irmanados por uma sensibilidade transformadora não é uma senha para escapar a um desastre iminente das sociedades capitalistas (essa seria a perspectiva iluminista da qual queremos fugir), mas é um elemento fundamental para uma conjugação entre filosofia, ensino e política capaz de romper com os círculos da dominação social. Pelo menos, é nesta direção que entendo essas aparentemente obscuras ideias que Benjamin apresenta ao final do texto sobre o surrealismo:

O coletivo também é corpo. E o corpo que ele ganha através da organização técnica só pode ser criado, em toda sua realidade política e objetiva, naquele espaço imagético que se nos torna familiar graças à iluminação profana. Somente quando na realidade corpo e espaço imagético se interpenetrarem tão profundamente que toda tensão revolucionária se transforme em inervação corporal coletiva, e toda inervação corporal do coletivo se transforme em descarga de energia revolucionária, só então a realidade terá superado a si própria... (Benjamin 1986, p.115)

\section{Heranças do corpo antropofágico}

O que significa, para a filosofia, dizer que esse nosso corpo coletivo é também africano e indigena? Não se trata, obviamente, apenas de uma exigência legal, de fato sancionada no Brasil em 2008 (lei 11.645, que institui o ensino de histórias e culturas afrobrasileiras e indígenas na educação básica). É necessário entender o que essa exigência legal importa para a filosofia, para o seu ensino na educação básica. Tratase da necessidade de uma experimentação corpo a corpo, tal como ensaiou Oswald de Andrade, com os limites da linguagem e do pensamento compreendidos e exercitados desde padrões "europeus" ou "ocidentais".

Em Caetés, romance de estreia de Graciliano Ramos, de 1933, o narrador e personagem, João Valério, que pretendia escrever um livro sobre os indios, desabafa:

Também aventurar-me a fabricar um romance histórico sem conhecer história! Os meus caetés não têm verossimilhança, porque deles apenas sei que existiram, 
andaram nus e comiam gente. Li, na escola primária, uns carapetões interessantes no Gonçalves Dias e no Alencar, mas já esqueci quase tudo. (...) Caciques. Que entendia eu de caciques?

Pode-se muito bem interpretar essa passagem como uma crítica ácida, irônica, a toda uma plataforma literária e cultural de fins dos anos 1920 e início dos anos 1930, em que a revalorização da figura do índio foi a tônica de muitos escritores e intelectuais, à esquerda e à direita. O mesmo talvez se possa dizer, ainda hoje, de qualquer tentativa de resgate da cultura indígena como horizonte de compreensão da nossa situação americana: o que entendemos nós de caciques? Mas essa seria uma forma equivocada de levar em conta o nosso "enraizamento tropical", quando do desafio de filosofar no Brasil ou na América do Sul. Essa forma parece prevalecer até mesmo em leituras positivas da antropofagia que privilegiam a questão da devoração como metáfora da apropriação da "cultura européia", a partir do mote oswaldiano "só me interessa o que não é meu". A armadilha aqui está em transformar em quase nada o gesto antropófago, congelando o paradoxo do escritor modernista que elege como "sua" uma cultura que the é alheia, a indígena, e como "outra" essa cultura européia que tão bem the constitui.

Contudo, o "indio tecnizado" não significa qualquer idealização da "apropriação" de aspectos da cultura indígena num mundo tecnizado. Em Oswald, a relação entre centro e periferia, entre a cultura européia que nos constitui e a herança indígena para a qual pouco atentamos é antes uma relação de guerra, conflito e reinvenção. Não se trata simplesmente de filtragem do alheio, nem muito menos de "sintese" ou visão idilica de uma possivel harmonização entre o mundo tecnológico e o primitivo. Trata-se, antes, de uma reconstrução, de uma reinvenção de atitudes, valores, em que elementos culturais indígenas são conjugados com elementos modernos, constituindo enigmas, gestos extremados de critica a aspectos autoritários e opressores da cultura ocidental. Ao menos cinco elementos (todos eles diretamente correlacionáveis com a perspectiva filosófica benjaminiana) ${ }^{5}$ se conjugam, em sentido preciso, na obra de Oswald: o matriarcado - critica ao patriarcado; uma ideia de sociedade regida pelo signo da alegria e da espontaneidade, contra o convencionalismo e a pompa; o comunismo como experiência surrealista ("Já tínhamos o comunismo. Já tínhamos a língua surrealista"); a técnica como elemento

5 Cf. Ceppas 2018. 
emancipador na arte, de modo geral (rádio, cinema, arquitetura), e na literatura em especial: novas linguagens: a "ingenuidade construtiva"; um experimentalismo linguístico-cognitivo: linguagem "sem fundo", pura superfície, metonímica, paratática, icônica.

Fernando Gerheim precisa este quinto ponto, como o aspecto mais radical do experimentalismo literário de Oswald:

O significado desliza pela superficie da frase sem penetrá-la, em parte como consequência do recurso à metonímia, que atua por contigüidade, descrevendo as coisas por suas qualidades concretas. As palavras são, em vez de símbolos, icones"(Gerheim 1999, p.37)

Partindo das relações entre linguagens oral, escrita e imagética, Oswald opõe uma "composição cinematográfica do pensamento" (Roteiros! Roteiros!) à tese de um "sentido transcendente" do texto. Segundo esta tese mais do que tradicional (a mais inextrincável das premissas de toda a metafísica ocidental, como mostrou Derrida: o fonologocentrismo), apesar do texto poder ser aceito como polissêmico, sua leitura pressupõe sempre a busca da explicação "a mais correta". Enquanto cena, ao contrário, o texto se presta antes ao saborear e à digestão, contra "as ideias", a favor do sinais.

Somos concretistas. As idéias tomam conta, reagem, queimam gente nas praças públicas. Suprimamos as idéias e as outras paralisias. Pelos roteiros. Acreditar nos sinais, acreditar nos instrumentos e nas estrelas (Manifesto antropófago, Oswald 1972)

É a própria noção de texto que se modifica, se alarga. Tudo é texto, dirá mais recentemente Derrida. Tal como Benjamin, Oswald estava interessado sobretudo em um curto-circuito estético, político e erótico, onde a superação possivel das opressões é também, e essencialmente, uma revolução da linguagem, da sensibilidade e das relações afetivas. $O$ elemento indigena e também o africano, com tudo o que carregam de mitológico, ritualístico, e também de brincalhão, dionisiaco, nos projetam esse sentimento de alteridade crítica radical no interior 
mesmo de nossa cultura. Eles carregam, acima de tudo, uma dimensão guerreira, de desafio e percepção da natureza radicalmente conflitiva das tensões que atravessam as antinomias de uma sociedade tão desigual e violenta, como é a sociedade brasileira. Oswald sempre se indispôs contra toda leitura harmonizadora da realidade nacional. Ao mesmo tempo, ele buscava incessantemente a superação através de uma iluminação estética, coletiva e catártica. $O$ bom humor, a alegria como prova dos nove.

O que pode significar ensinar filosofia no ensino médio numa sociedade como a brasileira? "Preparar para a cidadania"? Apresentamos, acima, elementos que nos ajudam a rever, repensar alguns aspectos que acreditamos centrais no debate sobre o tema. Em primeiro lugar, se admitimos que filosofia e democracia são termos indissociáveis, é preciso repensá-los de modo radical, partindo do princípio que suas tensões não se resolvem apenas com mais e melhor "esclarecimento". Duas dimensões essenciais do debate foram chamadas a comparecer: a questão da relação entre filosofia e atualidade, com o auxilio de Walter Benjamin, e a questão de uma possivel apropriação da herança indígena na cultura americana, através do projeto antropofágico de Oswald de Andrade, enquanto plataforma teórica e cultural que nos ajudaria a reconhecer e ultrapassar os limites de uma "formação escolar e filosófica europeia", limites que podemos identificar no reforço de concepções de mundo, dos seres humanos e da sociedade baseadas na identidade e no suposto universal do homem branco europeu.

Levar em conta esses elementos, hoje, como horizonte de sentido do filosofar com a multidão, nos trópicos, significa um imenso desafio. Estamos vivendo, novamente, um momento de tensionamento político, onde algumas das forças mais reacionárias da sociedade se unem, em nome da garantia dos privilégios de uma elite com a qual se identificam, sob pretexto do combate à corrupção, dentre outras coisas, para reverter o pouco avanço social possível de ser alcançado por uma coalizão política para lá de moderada, em grande parte também conservadora. Não é a primeira nem a segunda vez que isto acontece em nossa história. Momentos como esse sempre escancaram o nivel de irracionalidade e de violência que marcam a elite brasileira, patrimonialista, patriarcal e preconceituosa, mas que também estão refletidas em traços conservadores da cultura popular. Filosofar com a multidão é estar disposto a enfrentar esses enormes obstáculos, com o máximo possivel de alegria e espírito guerreiro, visando uma convivência mais solidária, plural e generosa. 


\section{Referências}

Adorno, T. (1989). Sobre Walter Benjamin, Madrid: Editorial Catedra.

Andrade, O. (1970). Do Pau-Brasil à antropofagia e às utopias, Obras Completas 6, Rio de Janeiro: Civilização Brasileira.

Benjamin, W. (1986). "O surrealismo. O último instantâneo da inteligência européia", in Documentos de cultura, Documentos de Barbárie, São Paulo: Cultrix.

Benjamin, W. (2012). "A obra de arte na era de sua reprodutibilidade técnica", Rio de Janeiro: Contraponto.

Ceppas, F. (2018). Afinidades entre os outsiders Walter Benjamin e Oswald de Andrade, Cadernos Walter Benjamin $\mathrm{n}^{\circ} 20$.

Gerheim, Fernando. (1999). Oswald de Andrade: de capa a colofão, Escrita, revista de pós-graduação em Letras da PUC-Rio, Rio de Janeiro, n²4, jan'/jun, p.37.

Rancière, J. (2003) Aux Bords du Politique. Paris : Folio. Rancière, J. (2009) A partilha do sensivel, São Paulo: Ed. 34. Rancière, J. (2014) O ódio à democracia, São Paulo: Boitempo.

Vernant, Jean-Pierre. (1986) As Origens do Pensamento Grego, São Paulo: Difel. 